\title{
O paradoxo da água na região das águas: o caso da Amazônia brasileira
}

Carlos Alexandre Bordalo

UFPA

p. $120-137$

revista

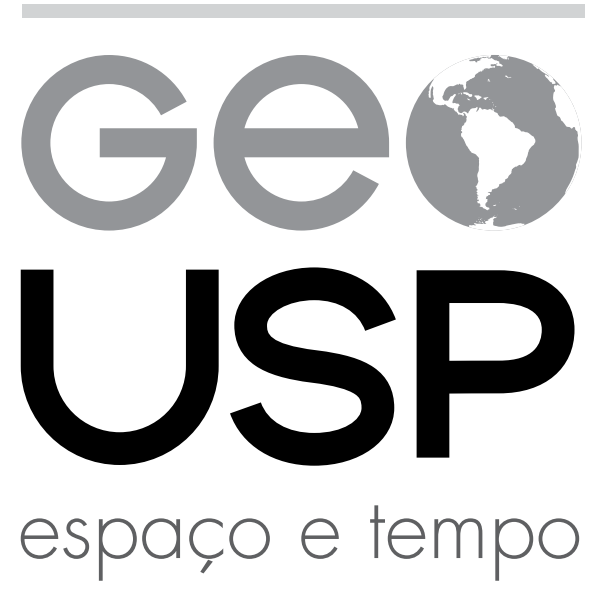

Volume $21 \cdot n^{\circ} 1(2017)$

ISSN 2179-0892
Como citar este artigo:

BORDALO, C. A. O paradoxo da água na região das águas: o caso da Amazônia brasileira. Geousp - Espaço e Tempo (Online), v. 21, n. 1, p. 120-137, abril. 2017. ISSN 2179-0892.

Disponível em: < http://www.revistas.usp.br/geousp/ article/view/107531>. doi: 10.11606/issn.2179-0892. geousp.2017.107531.

\section{(c) $(1) \otimes$}

Este artigo está licenciado sob a Creative Commons Attribution 4.0 License. 


\title{
O paradoxo da água na região das águas: o caso da Amazônia brasileira
}

\section{Resumo}

Neste início de século, o Conselho Mundial da Água já organizou cinco Fóruns Mundiais da Água, em que se apresentaram dados de uma crise eminente no abastecimento de água doce. Tema também apresentado pela ONU e sobre o qual todos devemos refletir. Aqui, apresentamos uma reflexão sobre o paradoxo da água na Amazônia brasileira, e veremos que, estando ela no trópico úmido e tendo a maior disponibilidade hídrica superficial, atmosférica e subterrânea do país, não há ali propriamente uma crise de disponibilidade de água doce, mas um acesso desigual à água potável, sendo que parte da população ainda não tem acesso a água tratada.

Palavras-chave: Amazônia. Água. Crise. Hidrogeografia. Hidropolítica.

\section{The water paradox in the water region: the case of the Brazilian Amazon}

\begin{abstract}
At the beginning of World Water Council has held five World Water Forums century where they were presented data of an imminent crisis in freshwater supply. Theme also presented by the UN and that should be reflected by all. Here we present a reflection on the paradox of water in the Brazilian Amazon and see in it, despite being located in the humid tropics and has the largest surface water availability, atmospheric and underground of the country, there is no availability of fresh water crisis, but the crisis of unequal access to drinking water, where part of the population does not have access to clean water.
\end{abstract}

Keywords: Amazon. Water. Crisis. Hydrogeographic. Hydropolitical. 


\section{Introdução}

Neste início de século o Conselho Mundial da Água já realizou cinco Fóruns Mundiais da Água: Kyoto, em 2003; Cidade do México, em 2006; Istambul, em 2009; Marselha, em 2012, e Daegu-Gyeongbuk, em 2015, onde se travaram guerras de paradigmas. $\bigcirc$ da água como direito humano universal versus a água como mercadoria, e o de uma crise eminente para no abastecimento de água doce ainda neste século.

A temática que envolve o abastecimento de água à população mundial, também está presente nos Informes das Nações Unidas sobre o Desenvolvimento dos Recursos Hídricos no Mundo (WWDR) (ONU, 2003).

Esses são temas que devem ser refletidos por todos, e aqui apresentamos uma reflexão sobre o paradoxo da água na Amazônia brasileira e veremos que nela não existe uma crise de disponibilidade de água doce, mas sim a crise do desigual acesso à água potável.

Segundo o Plano Nacional de Recursos Hídricos (PNRH, 2003, 2006) é no Norte do Brasil o maior índice de disponibilidade per capita de água doce do país, reunindo alta vazão específica com baixa densidade populacional, como verificado nas Regiões Hidrográficas Costeira Norte, com 1,8 milhão $\mathrm{m}^{3} /$ hab ano, do rio Amazonas com 455 mil $\mathrm{m}^{3} /$ hab ano, e na vertente oeste do Tocantins, entre as sub-bacias dos rios Araguaia e Pará, próximas a $150 \mathrm{mil} \mathrm{m} 3 /$ hab ano.

Contudo, ao analisamos os dados de 2005-09 divulgados pelo Sistema Nacional de Informações sobre Saneamento (SNIS) (Brasil, 2011), da população com índice total de abastecimento de água, verificamos que nos sete estados da região Norte, que juntos correspondem a Amazônia brasileira, apenas os estados do Tocantins e Roraima se aproximavam da média nacional em que entre 81 a 90\%. Somente o Amazonas entre 61 a 80\%. Acre, Amapá e Rondônia com índices entre 41 a 60\% de atendimento, ficando em último e trágico lugar, o Pará estava com um medíocre índice de menos de 40\%. Mas os índices de atendimento total de água para a população dos municípios desses estados mostraram que a distribuição espacial desses serviços era ainda mais grave. Visto que na grande maioria dos municípios esse índice estava abaixo de 50\% da população atendida e apenas um número muito reduzido de municípios, com um destaque para as capitais dos estados, esses serviços estariam atendendo mais de $70 \%$ da população.

Já a Pesquisa Nacional de Saneamento Básico realizada pelo Instituto Brasileiro de Geografia e Estatística (IBGE, 2010) mostrou que, mesmo com os avanços no país em relação ao período 2000-2008, onde houve um crescimento da ordem de $23 \%$ no número de domicílios abastecidos de água por rede geral, o quadro de precariedade desse serviço na região Norte do país ainda era muito evidente, visto que para o mesmo período houve apenas um discreto crescimento da ordem de 2,25\%. Pois o número de domicílios abastecidos por rede geral de água na região Norte, subiu irrisoriamente de $44,3 \%$ em 2000, para 45,3\% em 2008. Contrastando com os dados que mostram um aumento no número de domicílios atendidos no país de 63,9\% em 2000, para 78,6\% em 2008. 
Em outro Diagnóstico dos Serviços de Água e Esgoto divulgado em 2013 (Brasil, 2013) os dados referentes aos níveis de atendimento com rede de água em 2009, mostram que o país já tinha $82,4 \%$ da população total atendida, contudo, a região Norte ainda estava em último lugar com $54,6 \%$ da sua população total atendida por esse serviço. Para a população urbana brasileira, esses índices chegavam a $93 \%$ e na população urbana na região Norte já chegavam a 67,9\%. Mas ainda bem distante da realidade das demais regiões brasileiras.

Esse paradoxo do acesso a água doce e tratada é extremamente visível e alarmante quando analisamos a realidade da população residente em 2010 na Amazônia brasileira (15.864,454 hab), como nos estados do Acre (733.559 hab), Amazonas (3.483,985 hab), Amapá (669.526 hab), Pará (7.581,051 hab), Rondônia (1.562,409 hab), Roraima (450.479 hab) e Tocantins (1.383.445 hab), que, mesmo estando numa região onde há duas grandes bacias hidrográficas, as dos rios Amazonas e Tocantins-Araguaia, ainda têm pouco acesso a água.

Se o problema não está na baixa disponibilidade hídrica - como ocorre no semiárido nordestino e em algumas regiões metropolitanas do país, por que as demandas urbanas da população amazônida não estão sendo atendidas satisfatoriamente? Que fatores estariam comprometendo a qualidade do sistema de abastecimento de água à população? A reflexão entre o controle público versus o controle privado da água no Brasil nos remete a uma leitura a cerca do debate mundial sobre a privatização na prestação de serviços de saneamento. Sobre o abastecimento de água, Siqueira (2005) nos pergunta: "Quem é mais capaz de garantir o acesso da população à água - o setor público ou o setor privado? Ou ambos por meio de parcerias adequadas?".

Essas questões, ora levantadas, refletem o ponto central desta pesquisa desenvolvida desde 2013, sob a coordenação de professores e alunos do Grupo de Pesquisa Geografia das Águas da Amazônia (GGAM), pertencentes a Faculdade de Geografia e Cartografia - FGC e do Programa de Pós-Graduação em Geografia - PPGEO da Universidade Federal do Pará (UFPA). Que é entendermos como a população amazônida, localizadas numa região rica em disponibilidade hídrica atmosférica, superficial e subterrânea vem tendo problemas no acesso aos serviços de abastecimento de água a partir dos modelos de gestão público e privado.

\section{Objetivos}

Compreender e explicar por que as demandas urbanas por água da população amazônida que é uma das regiões mais ricas do país em água doce, não estão sendo atendidas satisfatoriamente. Que fatores estariam comprometendo a qualidade dos sistemas de abastecimento de água à sua população.

\section{Metodologia}

Nesta pesquisa, procuramos entender e explicar as reais explicações para essa inacessibilidade social à água na Amazônia brasileira, considerada a "região das 
águas". Para obter as respostas, levantaram-se dados bibliográficos e documentais, posteriormente analisados sobre o tema "crise da água" no mundo e no Brasil. E a interpretação e análise dos dados estatísticos como: Pesquisa Nacional de Saneamento Básico - PNSB/IBGE (2010), Plano Nacional de Recursos Hídricos (PNRH, 2006), Sistema Nacional de Informações do Saneamento (SNIS) do Ministério das Cidades (Brasil, 2011, 2013), Atlas Brasil da Agência Nacional das Águas (ANA, 2010), Atlas de Saneamento do IBGE (2011) e do Ranking do Saneamento do Instituto Trata Brasil (2014).

\section{Entendendo melhor a "crise" mundial da água, a hidropolítica}

Diante do atual dimensionamento e mapeamento da disponibilidade quantitativa e qualitativa da água doce no mundo, a ONU apresentou em março 2003 em Kyoto, Japão, durante a realização do Terceiro Foro Mundial sobre a Água o "Ano Internacional da Água Doce", a publicação do primeiro Informe das Nações Unidas sobre o Desenvolvimento dos Recursos Hídricos no Mundo (WWDRl) "Água para todos, Água para vida". Apresentando a nível mundial um dos mais importantes debates deste novo século, que nortearam a sobrevivência da humanidade e do próprio planeta, diante da crise mundial da água doce.

O referido informe (ONU, 2003) apresenta o primeiro resultado do estudo organizado pela ONU desde o ano de 2000 por meio do Programa Mundial de Avaliação dos Recursos Hídricos (WWAP) (ONU, 2003), do qual participam conjuntamente mais de 23 agências da própria ONU e secretariado pela Unesco. Com os resultados obtidos a partir dos dados da Organização Mundial de Meteorologia e de outras instituições, e cruzados com os dados fornecidos nos indicadores sociais, econômicos e demográficos, pode-se, então construir cenários sobre a oferta e demanda mundial por recursos hídricos para a segunda metade deste século.

A "crise" da água doce no mundo se faz presente de duas formas, uma que envolve a quantidade suficiente de água doce, seja as superficiais contidas nas bacias hidrográficas, ou as subterrâneas armazenadas nos aquíferos ou precipitas na forma de chuva, e a sua qualidade em relação aos desejáveis parâmetros físicos, químicos e bacteriológicos, que permitam um potencial (oferta) disponibilidade hídrica para atenderem as reais demandas atuais e futuras em relação às diferentes formas de uso, rural, doméstico e industrial.

Segundo o WWDRl (ONU, 2003),

Por crisis del agua se entiende la falta, actualmente crónica y muy extendida, de suministros de agua potable de buena calidad y precio razonable y de servicios de saneamiento, junto a la elevada incidencia de enfermedades ligadas, la destrucción del agua de ríos y lagos.

Em outro relatório divulgado pela ONU para celebrar o dia mundial da água "Agua limpia para un mundo sano" foi destacado que: 


\begin{abstract}
Aunque se estima que más del $90 \%$ de la población mundial utilizará una fuente mejorada de acceso al agua potable antes de 2015, es preciso realizar grandes esfuerzos para alcanzar la meta en materia de servicios de saneamiento fijada en los Objetivos de Desarrollo del Milenio. Por ejemplo, durante más de 16 años (entre 1990 y 2006) la proporción de personas carentes de unos servicios de saneamiento mejorados disminuyó en sólo un $8 \%$. Teniendo en cuenta el crecimiento demográfico, antes de 2015 aproximadamente 2.400 millones de personas seguirán careciendo de acceso a unos servicios básicos de saneamiento en 2015. (Un water [...], 2010)
\end{abstract}

Essa interpretação apresentada pela ONU sobre a "crise" mundial da água doce, esta diretamente relacionada às diferentes formas de apropriação, uso e conservação dos recursos hídricos, por parte da população dos países desenvolvidos, em desenvolvimento e subdesenvolvidos, onde a questão principal é a desigual oferta entre esses países, do abastecimento de água potável de boa qualidade a preços razoáveis, e dos serviços de saneamento, fundamentais à melhoria da qualidade de vida dessas populações.

Mais recentemente a ONU, em 2012, apresentou o 40 Informes das Nações Unidas sobre o Desenvolvimento dos Recursos Hídricos no Mundo (WWDR4) quando o secretário-geral Ban Kin-moom, destacou que:

Universal access to safe drinking water and water resources is an imperative that cuts across all internationally agreed development objectives, including the Millennium Development Goals. Improving access to water improves health and education outcomes. It increases agricultural productivity. It is a force for gender equality and women's empowerment. (Unesco, 2012).

A "crise" que envolve o atendimento ao aumento mundial do consumo de água potável, no caso, a crescente demanda por água em boa quantidade e qualidade, destinada aos usos agrícola, industrial e doméstico, relaciona-se não só à distribuição espacial e temporal desse recurso, mas à capacidade de atender a essas diferentes demandas com custo razoável e sem conflitos.

Mas, se por um lado nos deparamos com situações de abundância no abastecimento de água para esses fins, na grande maioria dos países desenvolvidos, o mesmo não se pode afirmar em relação aos países em desenvolvimento e, principalmente, aos subdesenvolvidos, visto que, na sua grande totalidade, o atendimento dessa demanda ainda é muito precário, ou mesmo ausente, caracterizando assim uma grande escassez hídrica.

Para Peter Gleick (1998), o problema do "risco" de escassez hídrica para o próximo milênio está relacionado à necessidade de uma mudança mais rápida de um novo paradigma que adote o manejo da água, voltado ao aumento da eficiência do sistema 
de abastecimento, bem como no tratamento e reutilização dos efluentes residenciais e industriais.

Para a ativista indiana Vandana Shiva (2006) a crise da água é a dimensão mais difusa, mais severa e mais invisível da devastação ecológica da Terra. E diz que um país enfrenta uma crise de água grave quando a água disponível é menor que mil metros cúbicos por habitante por ano e quando essa disponibilidade anual por habitante cai abaixo de quinhentos metros cúbicos, compromete-se cruelmente a sobrevivência da população.

Shiva (2006) também argumenta que a "baixa" disponibilidade hídrica por habitante/ anos, não se deve apenas a fatores naturais regidos pelo ciclo hidrológico, ou decorrente do grande crescimento demográfico visto em alguns países asiáticos como China, Índia e Paquistão. Ela explica que no ultimo século a taxa de retirada da água causada pelo seu uso excessivo, excedeu a do crescimento populacional pelo fator de dois e meio.

Essa grande retirada excessiva de água estaria relacionada ao uso de tecnologias poderosas que ao obedecerem a filosofia do desenvolvimento que violam o ciclo da água, apenas levam ao esgotamento da água e não ao seu melhor uso, fato que levaria à escassez da água.

Tentando explicar a "crise" da água, Shiva (2006) diz que há dois paradigmas: o do mercado e o ecológico. $\bigcirc$ paradigma do mercado vê a escassez de água como uma crise que resulta na falta do comércio de água, pois a sua comercialização a preços mais elevados levariam a melhor conservação, pois a oferta da água estaria regulada pelas leis de mercado. Já para o paradigma ecológico a crise da água é uma crise ecológica com causas comerciais, mas sem soluções de mercado. E para acabar com essa crise, só com o rejuvenescimento da democracia ecológica.

Outros ativistas que também pesquisam e nos alertam sobre a "crise da água no mundo", são Maude Barlow e Tony Clarke (2003). Eles chamam atenção para um "Alerta Vermelho" em relação ao problema da escassez da água, pois de acordo com os dados das Nações Unidas, 31 países do mundo atualmente enfrentam escassez de água. Mais de um bilhão de pessoas não teriam nenhum acesso à água limpa para beber e quase três bilhões não teriam nenhum acesso aos serviços de saneamento público. Segundo esses dados, as previsões que até o ano de 2050, o mundo terá 2,6 bilhões de pessoas a mais do que tem hoje, mas $2 / 3$ dessas viverá em condições de séria escassez de água, e $1 / 3$ com escassez absoluta. E a demanda por água excederá a disponibilidade em $56 \%$.

Mas Barlow e Clarke (2003) nos explicam que as causas a esse "alerta vermelho" não estariam apenas relacionadas aos problemas de baixa disponibilidade hídrica e o elevado crescimento populacional, mas também ao acesso desigual à água doce e tratada. E esse alerta seria maior para os países do Terceiro Mundo, pois segundo a $O N U$, antes de 2025, a grande maioria das megalópoles, nas quais mais de 50\% da população que não tem nenhum acesso à água limpa, fica situada no Terceiro Mundo e a taxa mais alta de crescimento dentro dessas cidades está nas favelas e que antes de 2030 mais da metade da população desses enormes centros urbanos será composta de moradores de favela 
sem acesso a qualquer tipo de serviço de água e saneamento básico.

Em outra obra, Barlow (2009) nos pergunta "para onde foi toda a água?" Ela nos apresenta três cenários que juntos estariam conspirando em direção à calamidade:

- Cenário um: O mundo está ficando sem água doce e a humanidade está poluindo, desviando e esgotando as fontes finitas de água da Terra, em ritmo perigoso que aumenta constantemente;

- Cenário dois: A cada dia, mais e mais pessoas estão vivendo sem acesso a água limpa e a crise global da água se tornou um símbolo muito poderoso da crescente desigualdade no mundo;

- Cenário três: Um poderoso cartel corporativo da água surgiu para assumir o controle de todos os aspectos da água a fim de obter lucro em benefício próprio.

Nessa mesma obra, Barlow (2009) no diz que neste início de milênio, foram publicados mais estudos, relatórios e livros sobre a crise global da água do que em todo o século que o precedeu. Ela destaca as informações do World Watch Institute que declarou "A escassez de água pode ser o desafio ambiental global menos valorizado de nossa época". E sobre a escassez da água, ela nos apresenta que o veredito final irrefutável é: O mundo está enfrentando uma crise hídrica devido à população, à poluição, à mudança climática e a uma onda de crescimento populacional de tamanha magnitude que quase dois bilhões de pessoas agora vivem em regiões do planeta que apresentam estresse hídrico. Além disso, a menos que alteremos nossos caminhos, até o ano de 2025, dois terços na população mundial enfrentaram a escassez hídrica.

Em outra obra mais recente, Barlow (2015) relata que em 2030, espera-se que a demanda por água supere a oferta em $40 \%$. Ela destaca ainda que quase a metade da população mundial estará vivendo em áreas de estresse e em 2075, o número de afetados poderá ser tão alto quanto sete bilhões de pessoas.

Outro importante estudioso do tema sobre a "crise da água" é o italiano Ricardo Petrella (2004), ele também argumenta que neste século a água suscitará três grandes questões, que envolvem todos os habitantes e as sociedades do mundo.

- (1) O acesso à água potável é um direito humano, por isso universal, indivisível e imprescritível, ou uma necessidade vital cuja satisfação passa pelos mecanismos de mercado?

- (2॰) A quem pertence à água? Trata-se de um bem comum (comum a quem, a que tipos de comunidades), ou trata-se de um bem apropriável, a título privado, de uma mercadoria vendável que podemos comprar como petróleo ou outro bem/mercadoria?

- (3o) É possível deter os processos de rarefação e de escassez crescente dos recursos hídricos do Planeta, garantindo a utilização das águas e a 
segurança de abastecimento para todos, segundo os princípios de uma gestão sustentável e solidária, ou devemos deixar a escolha, quanto à locação dos recursos hídricos do Planeta, às lógicas geopolíticas dos Estados nacionais e às lógicas financeiras dos detentores privados de capital, enfraquecendo, assim, as formas e as práticas de democracia representativa e participativa?

Na geografia contemporânea, o debate acerca da crise mundial da água doce ainda é muito recente e restrito. Ainda são poucos os geógrafos famosos que se envolvem com o tema crise da água. Visto que, ao longo de décadas, a água vinha sendo tratada equivocadamente como um recurso natural abundante e inesgotável. Visão errônea que ocultou por muitos anos os verdadeiros valores sanitário, cultural, social, econômico e geopolítico que a água tem e terá ainda mais neste século, pois para muitos ela já é o "ouro azul".

Quem trabalha com a ideia de uma hidropolítica para explicar o problema da "crise mundial da água", é o geógrafo tunisiano Mohamed Bouguerra (2004), quando pergunta se existe uma escassez ou má gestão da água?

$\mathrm{Na}$ tentativa de nos responder se existe uma escassez ou má gestão da água? Bouguerra (2004) nos responde que a água é "um recurso bem mal repartido" e que neste século será alvo de grandes tensões locais e conflitos internacionais. Ele fala de uma hidropolítica para compreender os conflitos pela água que existem nos cinco continentes. E os conflitos acontecem seja entre Estados Turquia-Síria, JordâniaIsrael, Índia-Bangladesh, Irã-Iraque, Namíbia-Lesoto, Senegal-Mauritânia, HungriaEslováquia, Uzbequistão-Kasaquistão-Quirquistão-Tadjiquistão, ou entre Estados federados como na Índia, na Malásia e nos EUA.

Sobre a tentativa de se definir a ideal quantidade de água disponível por países ou por habitante/ano, Bouguerra (2004) destaca o Índice das Necessidades de Água Doce Habitante proposto pelo Hidrólogo Marlin Falkenmark, que o apresenta na tentativa de se definir o conceito de "estresse hídrico" e de "penúria de água". Desta forma se dirá que um país está em estado de estresse hídrico se a disponibilidade anual de água for inferior a $1.700 \mathrm{~m}^{3}$ por pessoa. Se ele se situar entre $1.700 \mathrm{e} 1.000$ $\mathrm{m}^{3}$ por cabeça, o país enfrentará, provavelmente, períodos de falta temporária ou ilimitada. Quando o abastecimento anual por pessoa é inferior a $1.000 \mathrm{~m}^{3}$, o país enfrenta a penúria.

Entre os poucos geógrafos brasileiros que pesquisam a "crise da água" na perspectiva da geografia política, podemos destacar Bertha Becker (2003) que nos explica que a escassez de água é a mais recente preocupação, sendo percebida e anunciada como verdadeira catástrofe mundial, a ponto de lhe serem atribuído um valor estratégico similar ao do petróleo no século XX e a denominação de "ouro azul". Ela também fala que uma verdadeira hidropolítica se configura no cenário mundial. 
Outro geógrafo brasileiro que também aborda a problemática da escassez da água na direção de uma hidropolítica é Wagner Ribeiro (2008), que a luz da Geografia Política, procura explicar que a crise da água esta relacionada à combinação de fatores naturais e sociais que permitem elaborar uma interpretação política dos recursos hídricos, ao que ele denomina de "A distribuição política da água".

Ribeiro (2008) nos explica que a distribuição física da água não obedece a critérios de renda, e sim decorre de processos naturais. A água como elemento natural depende do ciclo hidrológico para ser reposta. Nesse processo incluem-se fatores climáticos, geológicos e outros relacionados ao uso do solo. E que existe muita polêmica em torno dos indicadores de água na Terra e que muitas visões exageram na escassez. E que a crise da água também é resultado de sua distribuição pelo planeta. Ela combina natureza a história, dando-lhe um caráter eminentemente geográfico.

Para este geógrafo existem várias maneiras de se mensurar a disponibilidade hídrica de uma unidade geográfica, bem como são apresentados vários índices para se tentar medir a escassez da água que pode ser física e econômica. Como o Índice de Pobreza de Água, que leva em consideração cinco aspectos: recursos disponíveis, acesso à água, capacidade da população em manejá-la, seu uso e a qualidade do ambiente em que ela ocorre.

Essa tarefa política em se analisar o debate político sobre o acesso e o controle da água, se confunde com o que entendemos ser uma verdadeira hidropolítica global, bem expressa tanto na geografia política, quanto na ecologia política.

Para os geógrafos amazônidas como Bordalo (2008) essa aproximação teórica e metodológica da geografia com a ecologia política permite um rico arcabouço na leitura e no entendimento de processos biofísicos e socioeconômicos, presentes nos temas que envolvem a gestão dos recursos naturais. Diferentemente da economia ambiental neoclássica, que defende que o mito da "escassez" da água resulta do alto crescimento populacional e da inexistência de propriedade privada, bem como da falta de uma regulação pelo mercado, a ecologia política, junto com a geografia política, que não dissociam natureza e sociedade e tempo e espaço, são capazes de ver melhor a clara manifestação dos interesses dos donos dos meios de produção de se apropriarem cada vez mais dos recursos naturais tidos como capital natural.

Para este geógrafo que procura explicar a "crise" mundial da água na vista numa perspectiva da Geografia Política, essa tarefa política em se analisar o debate político sobre o acesso e o controle da água, se confunde com o que entendemos ser uma verdadeira hidropolítca global, bem expressa tanto na geografia política, quanto na ecologia política. (Bordalo, 2012).

\section{Podemos falar em "crise" de água na Amazônia brasileira?}

Falar em "crise" da água no Brasil parece ser uma grande contradição em um país com grande parte do seu território localizado na Zona Climática Intertropical, com índices de pluviosidade média anual em torno de $1.800 \mathrm{~mm}$, e que tem extensas 
bacias hidrográficas (Amazonas, Tocantins, São Francisco, Paraná, Paraguai e do Uruguai), responsáveis por $12 \%$ (1,488 milhão $\left.\mathrm{m}^{3} / \mathrm{s}\right)$ da água doce dos rios no mundo e $53 \%$ (334 $\left.\mathrm{mil} \mathrm{m}^{3} / \mathrm{s}\right)$ do total da América do Sul.

Mas, essa recente situação do risco de "crise" quantitativa e qualitativa no abastecimento de água doce no Brasil, principalmente nas regiões metropolitanas, foi apresentada no documento base de referência do Plano Nacional de Recursos Hídricos (PNRH, 2003). Nele, foram utilizados dados por municípios, como: físicos, demográficos, econômicos, sociais, de saúde e saneamento, pesquisados pelo IBGE, e uma farta referência bibliográfica, que mostram uma situação de grandes desigualdades regionais em relação à abundância e escassez hídrica no país.

Quando os dados físicos de vazão específica média são associados aos dados demográficos da densidade populacional das regiões hidrográficas, aparecem discrepâncias geográficas ainda maiores no território brasileiro, mesmo que sejamos classificados como "ricos" por termos uma vazão média por habitante, em 2000, na ordem de $29.774 \mathrm{~m}^{3} /$ habitante/ano.

Segundo o PNRH (2006), é no Norte do Brasil o maior índice de disponibilidade per capita do país, reunindo alta vazão específica com baixa densidade populacional, como verificado nas regiões hidrográficas: Costeira Norte, com 1,8 milhão $\mathrm{m}^{3} /$ hab ano, do rio Amazonas com $455 \mathrm{mil} \mathrm{m}^{3} / \mathrm{hab}$ ano, e na vertente oeste do Tocantins, entre as sub-bacias dos rios Araguaia e Pará, próximas a $150 \mathrm{mil} \mathrm{m}^{3} / \mathrm{hab}$ ano.

Em relação aos dados de saneamento básico e as implicações para a saúde pública tratados no PNRH, foram utilizados e cruzados os dados do Censo Demográfico (IBGE, 2010a) com a com a PNSB (IBGE, 2010). Os resultados mostraram que, no Brasil, 22,2\% (9.935.708) dos domicílios particulares permanentes não contavam com rede de distribuição de água e utilizam soluções alternativas para o suprimento de água, e que, na sua maioria, (5.293.008) estão localizados nas regiões Norte e Nordeste do país.

Segundo dados da PNSB (IBGE, 2010), mesmo com os avanços no país em no período 2000-2008, quando houve um crescimento na ordem de $23 \%$ no número de domićlios abastecidos de água por rede geral. O quadro de precariedade deste serviço na região Norte do país, ainda é muito evidente, visto que para o mesmo período houve apenas um discreto crescimento na ordem de $2,25 \%$. Pois o número de domicílios abastecidos por rede geral de água na região Norte, subiu irrisoriamente de 44,3\% em 2000, para 45,3\% em 2008. Contrastando com os dados da mesma pesquisa que mostram um aumento no número de domicílios atendidos no país de 63, $9 \%$ em 2000, subiu para 78,6\% em 2008.

Analisando os dados referentes ao volume de água distribuída por dia, tratada e sem tratamento, por grandes regiões do Brasil, verifica-se que em 2008 o país já apresentava um percentual de $92,9 \%$ do volume de água distribuído diariamente com tratamento e apenas $7,1 \%$ do volume de água distribuído diariamente sem tratamento. 


\section{Figura 1}

\section{Gráfico de domicílios abastecidos de água por rede geral}

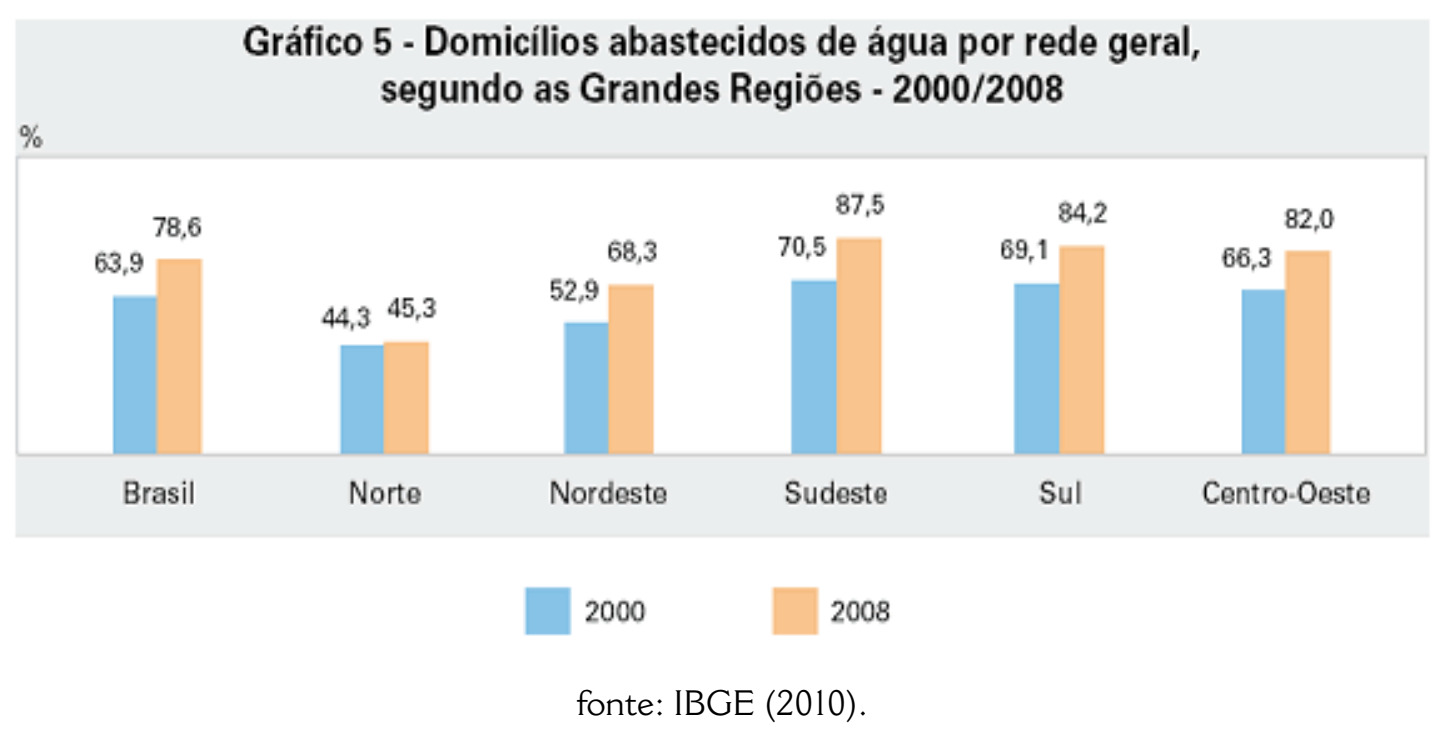

Mas esses percentuais se mostram desiguais quando analisamos os percentuais pelas 5 Grandes Regiões, pois enquanto as regiões Nordeste, Sudeste, Sul e CentroOeste apresentavam um percentual do volume de água distribuído diariamente com tratamento acima dos $91 \%$, na região Norte esse percentual ainda estava bem abaixo, com apenas $74,3 \%$. Já para o volume de água distribuído diariamente sem tratamento, essas quatro regiões têm um percentual abaixo dos $8,8 \%$, enquanto na região Norte esse percentual é superior em mais de três vezes com $25,7 \%$.

A leitura dos dados da Pesquisa Nacional de Saneamento Básico (PNSB, 2008), revela as desigualdades regionais na distribuição de água em todo o país. Nas áreas urbanas, o abastecimento de água prevalece sobre as rurais, havendo uma correspondência direta entre a densidade populacional dos municípios e a cobertura das redes. Por essa razão, a região Sudeste se destaca como a mais fartamente servida pelo abastecimento água tratada, tendo praticamente atingido a universalização do serviço em suas áreas de maior adensamento urbano-populacional.

Quando analisamos os dados de 2005-09 divulgados pelo SNIS (Brasil, 2011), referente aos índices de atendimento total de água para a população dos estados da região Norte, verificou-se que a distribuição espacial desses serviços era ainda mais grave. Visto que em 4 dos 7 estados esse índice estava abaixo de $60 \%$ da população atendida (Bordalo et al., 2015).

Segundo esses dados apenas os estados do Tocantins e Roraima se aproximavam da média nacional, entre 81 a $90 \%$ da população com índice total de abastecimento de água. Somente o Amazonas estava entre 61 a 80\%. Acre, Amapá e Rondônia com índices entre 41 a $60 \%$ de atendimento, ficando em último e trágico lugar, o Pará com um medíocre índice de menos de $40 \%$.

Em outra pesquisa mais recente do SNIS (Brasil, 2013), observa-se que em 19 
estados o índice de atendimento urbano com rede de água em 2011 foi superior a 90\%, enquanto em outros três, o índice situou-se próximo ou abaixo dos $50 \%$ : Rondônia, 54,8\%; Pará, 53,9\%; e Amapá, 41,7\%.

\section{Figura 2}

Mapa de água tratada em relação ao total de água distribuída por município (\%)

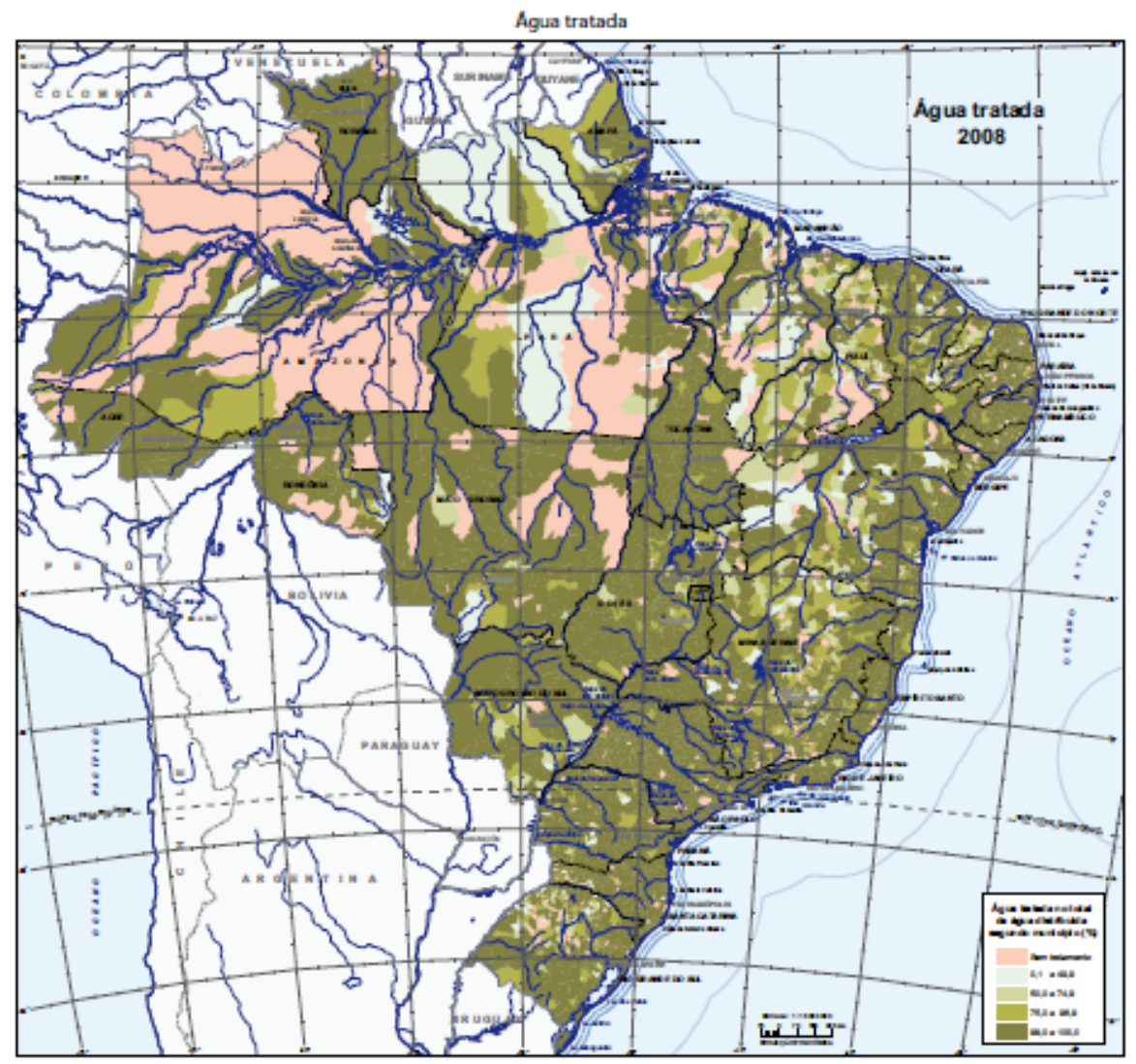

fonte: IBGE (2011).

Quanto às capitais de estado, as informações fornecidas ao SNIS em 2009 resultaram em índice de atendimento urbano com rede de água igual a 100\% para nove capitais: Boa Vista-RR, Palmas-TO, Belo Horizonte-MG, Vitória-ES, São Paulo-SP, Curitiba-PR, Florianópolis/SC, Porto Alegre-RS, e Goiânia-GO.

Outras capitais situaram-se em patamar muito próximo dos 100\%: Cuiabá-MT, 99,7\%, Brasília-DF, 99,4\%; e Aracaju/SE, 99,1\%. Há também algumas capitais de estados com índices muito baixos, como Macapá-AP, 42,8\%, e Porto Velho/RO, apenas $38,1 \%$.

Analisando o quadro e mapa (Figura 4) que apresentam a visualização espacial do índice de perdas na distribuição para todo o conjunto de prestadores de serviços participantes do SNIS em 2011, com valores médios distribuídos por faixas percentuais, segundo os estados brasileiros. 


\section{Figura 3}

Mapa da distribuição no Brasil dos índices de atendimento urbano de água
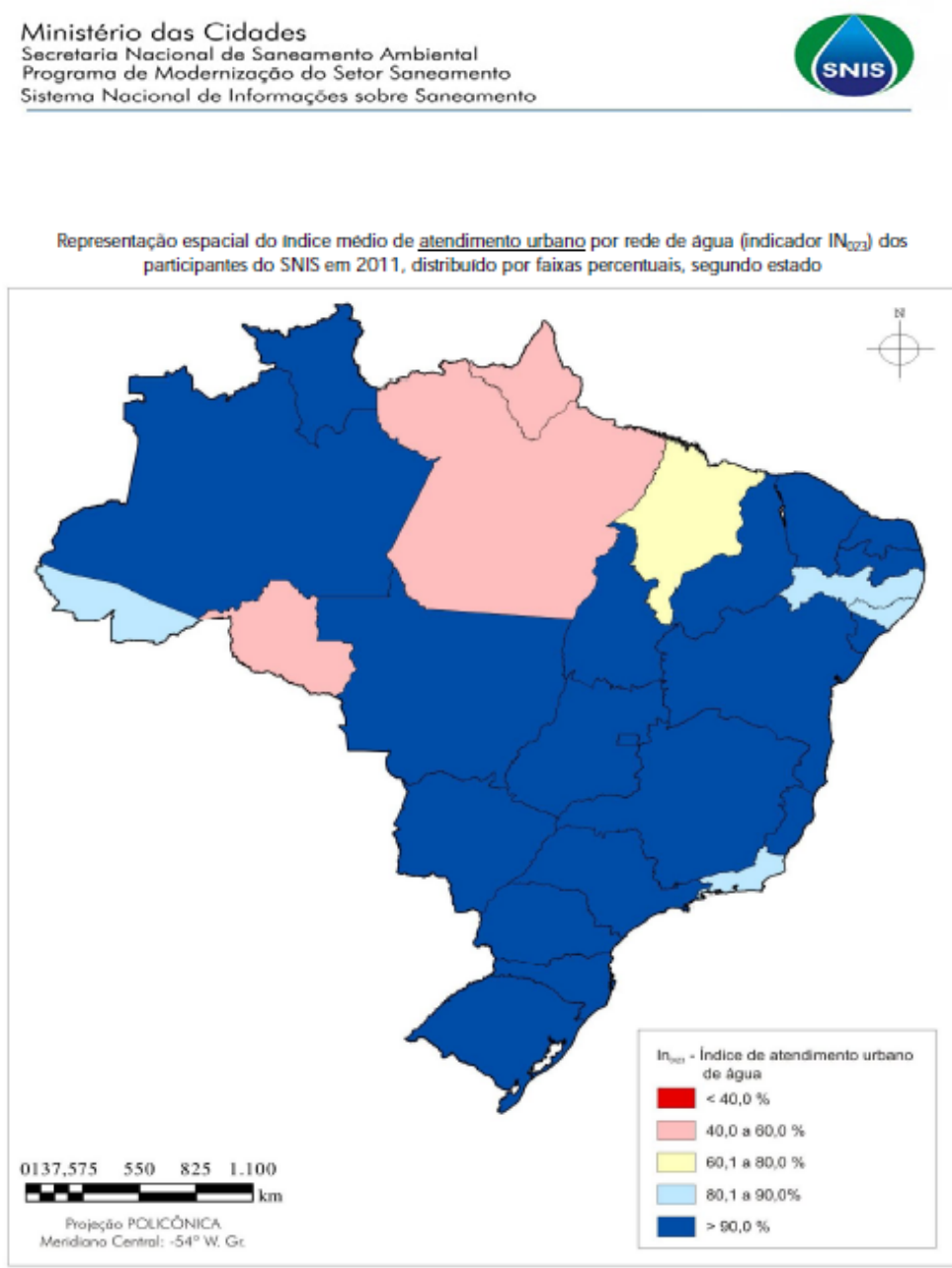

Fonter: Molho munidipol diginal do Brosil, Base de Informosces Municipas 4, 18GE, 2003, Dodos: SN15, 2011.

fonte: SNIS (Brasil, 2011).

Percebemos que nenhum estado brasileiro conseguiu situar-se na melhor faixa, índice de perda na distribuição menor que $20 \%$, sendo que o Distrito Federal enquadrou-se na melhor situação, porém na segunda melhor faixa, entre 20 e 30\%. Na faixa entre 30 e 40\%, situaram-se 12 estados: Tocantins (região Norte), Ceará e Bahia (região Nordeste), Espírito Santo, Minas Gerais, Rio de Janeiro e São Paulo (região Sudeste), Paraná, Santa Catarina e Rio de Grande do Sul (região Sul), Goiás e Mato Grosso do Sul (região Centro-Oeste), na ordem das regiões geográficas brasileiras. Na última faixa, maior que 40\%, restaram 14 estados: Acre, Amazonas, Amapá, Pará, Rondônia e Roraima (região Norte), Alagoas, Maranhão, Paraíba, Pernambuco, Piauí, Rio Grande do Norte e Sergipe (região Nordeste), Mato Grosso (região Centro-Oeste), também na ordem das regiões geográficas brasileiras. Como se observa, na pior faixa encontram-se majoritariamente estados do Norte e Nordeste, mais um estado no Centro-Oeste (IBGE, 2011). 
Figura 4

Quadro e Mapa da distribuição espacial dos índices de perda na distribuição de água Indice de perdas na distribuiçào (indicador $\mathbb{I N}_{\text {Das: }}$ )
dos prestadores de serviços participantes do SNIS em 2011, segundo estado, regiào e Brasil

\begin{tabular}{|c|c|}
\hline Estado / Reglao & $\mathrm{IN}_{\mathrm{Sa3}}\left(\mathrm{O}_{2}\right)$ \\
\hline Acre & 64,7 \\
\hline Arnazonas & 49,7 \\
\hline Amapa & 73,3 \\
\hline \begin{tabular}{|l|} 
Para \\
\end{tabular} & 42,3 \\
\hline Rondonla & 53,8 \\
\hline \begin{tabular}{|l} 
Roraima \\
\end{tabular} & 58,1 \\
\hline \begin{tabular}{|l} 
Tocantins \\
\end{tabular} & 34,6 \\
\hline \begin{tabular}{|l|} 
Norte \\
\end{tabular} & 49,7 \\
\hline \begin{tabular}{|l|} 
Alagoas \\
\end{tabular} & 59,6 \\
\hline Banla & 38,2 \\
\hline \begin{tabular}{|l|} 
Ceara \\
\end{tabular} & 35,3 \\
\hline \begin{tabular}{|l|} 
Maranthao \\
\end{tabular} & 55,9 \\
\hline \begin{tabular}{|l|} 
Paralba \\
\end{tabular} & 45,9 \\
\hline \begin{tabular}{|l|} 
Pernambuco \\
\end{tabular} & 65,7 \\
\hline \begin{tabular}{|l|} 
Plaul \\
\end{tabular} & 59,1 \\
\hline \begin{tabular}{|l|} 
Rlo Grande do Norte \\
\end{tabular} & 57,4 \\
\hline Sergipe & 60,3 \\
\hline \begin{tabular}{|l} 
Nordeste \\
\end{tabular} & 51,4 \\
\hline \begin{tabular}{|l} 
Espirito Santo \\
\end{tabular} & 34,6 \\
\hline \begin{tabular}{|l|} 
Minas Gerals \\
\end{tabular} & 33,1 \\
\hline \begin{tabular}{|l|} 
Rio de Janeiro \\
\end{tabular} & 32,8 \\
\hline Sao Paulo & 35,2 \\
\hline \begin{tabular}{|l|} 
Sudeste \\
\end{tabular} & 34,3 \\
\hline \begin{tabular}{|l|} 
Parand \\
\end{tabular} & 33,1 \\
\hline \begin{tabular}{|l|} 
Rio Grande do Sul \\
\end{tabular} & 39,0 \\
\hline \begin{tabular}{|l|} 
Sarta Catarina \\
\end{tabular} & 33,6 \\
\hline \begin{tabular}{|l|} 
Sul \\
\end{tabular} & 35,6 \\
\hline \begin{tabular}{|l|} 
Distrito Federal \\
\end{tabular} & 24,8 \\
\hline \begin{tabular}{|l} 
Golds \\
\end{tabular} & 31,6 \\
\hline \begin{tabular}{|l|} 
Mato Grosso do Sul \\
\end{tabular} & 31,8 \\
\hline Mato Grosso & 45,9 \\
\hline \begin{tabular}{|l} 
Centro-Oeste \\
\end{tabular} & 33,6 \\
\hline Brasil & 38,8 \\
\hline
\end{tabular}

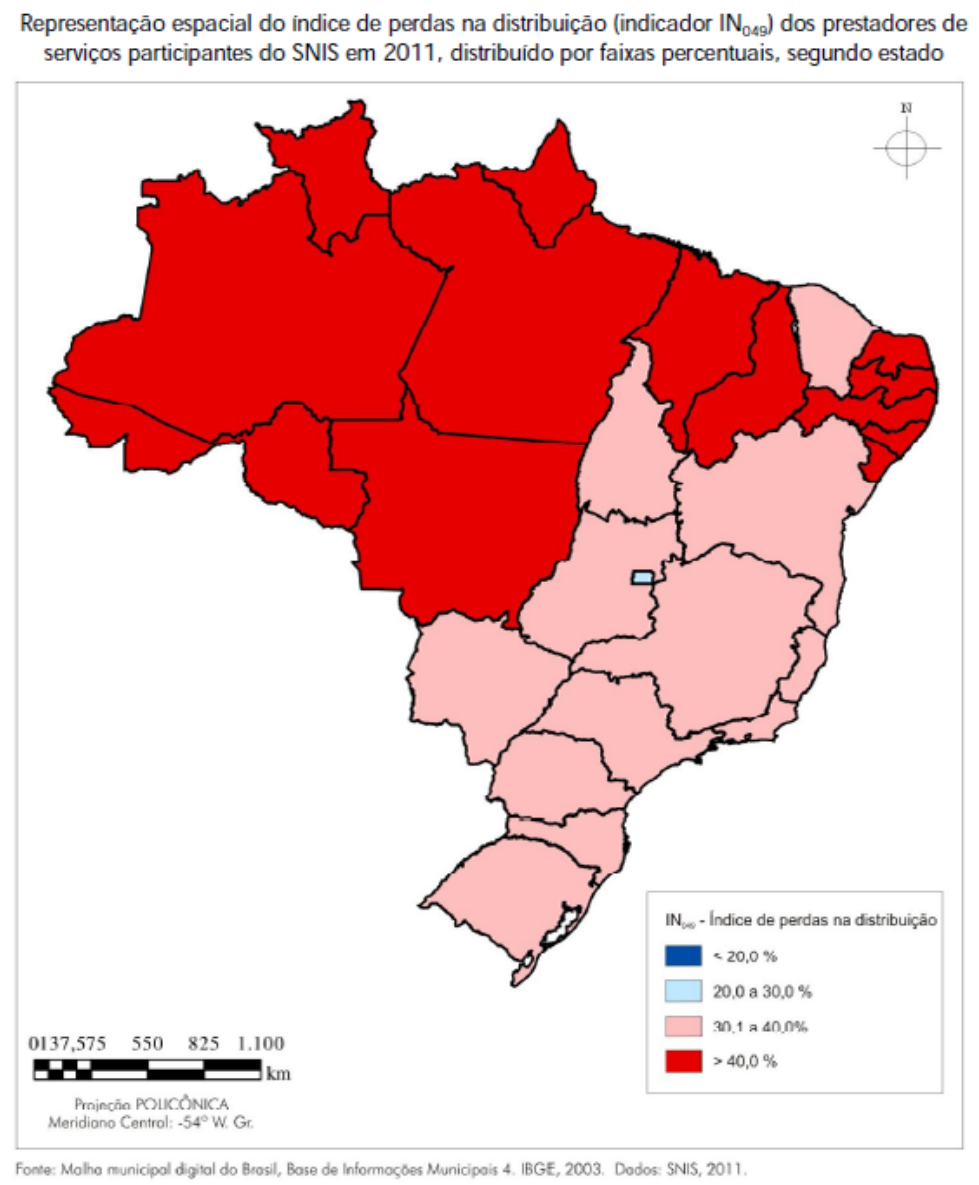

fonte: SNIS (Brasil, 2011).

Esse índice maior de $40 \%$ de perda na distribuição de água à população em 6 estados da Amazônia brasileira, só pioram o já precário quadro dos serviços de abastecimento de água, que além de só atingirem 45,3\% dos domicílios em 2008, principalmente nas capitais e regiões metropolitanas, em detrimento da população rural. Ainda são sujeitas a perdas significativas do volume de água tratada que tanto faz falta nas torneiras dos amazônidas.

Já nos dados do SNIS (Brasil, 2011), referente aos índices de atendimento total de água para a população dos municípios dos estados da região Norte, verifica-se que a distribuição espacial desses serviços era ainda mais grave. Visto que na grande maioria dos municípios esse índice esta abaixo de $50 \%$ da população atendida e apenas um número muito reduzido de municípios, com um destaque para as capitais dos estados, esses serviços estariam atendendo mais de $70 \%$ da população.

Contudo, esses dados do SNIS $(2005,2009)$ e da PNSB (2008) mostram apenas as informações referentes à existência de empresas públicas ou privadas que estão fornecendo serviços de abastecimento de água à população dos municípios brasileiros que têm rede de abastecimento de água potável. 
A existência nos municípios de uma companhia pública ou privada responsável pelos serviços de abastecimento de água, não garante que haja rede geral de água potável atendendo a todos os domicílios, bem como, que estes serviços funcionem durante as 24 horas sem interrupção e de boa qualidade.

O Instituto Trata Brasil (2014), com dados do SNIS (2012), avaliou entre os cem maiores municípios do território nacional aqueles que tiveram os vinte melhores e os dez piores índices de abastecimento total de água, cujos piores índices estão na região Norte e três no estado do Pará. Belém é apontada como o 92० do ranking (72,63\%), Santarém (45,78\%), Macapá (39,99\%), Porto Velho (32,89\%) e Ananindeua $(27,20 \%)$ como o último colocado entre os dez piores.

\section{Considerações finais}

Com base nos argumentos dos autores citados e em geógrafos como Gleick (1998), Becker (2003), Bouguerra (2004), Ribeiro (2008), Bordalo (2008, 2012) e Bordalo e outros $(2012,2015)$, fica claro que a crise mundial da água doce não está só na diminuição da disponibilidade absoluta (oferta menor que a demanda) devido ao intenso crescimento demográfico, que leva à escassez hídrica, tampouco ela deva ser regulada exclusivamente pelas leis do mercado, mas sim na crise do desigual acesso à água, bem como nas suas diferentes formas de uso e consumo, díspares entre países ricos e pobres. Assim, cria-se o que Becker chama de "paradoxo abundância do recurso" versus "inacessibilidade social", situação bem explicada pela geografia política, pela ecologia política e pela geoeconomia.

Concordamos com esses autores que a "crise da água" está no atual paradigma de uso da água, marcado pelo discrepante consumo e desperdício entre países ricos e pobres, ou mesmo internamente, entre populações ricas e pobres. Enquanto se projetam milhões de habitantes sem acesso a água tratada em 2025 e bilhões em 2050, alguns milhares a usam exageradamente a preços exorbitantes.

Compreender e explicar esse paradoxo da água na Amazônia tornou-se uma tarefa grandiosa e estratégica, pois, num cenário amazônico marcado por uma significativa riqueza hídrica, seja superficial, atmosférica ou subterrânea, com uma população rural e urbana extremamente vinculada aos rios, lagos e igarapés, nos assombra e preocupa saber que mais da metade da população amazônica em 2008 ainda estava sujeita a consumir água de má qualidade, ou até mesmo não tinha acesso a ela.

Se a crise da água na Amazônia brasileira não é causada pela baixa disponibilidade hídrica, nos resta concluir, após analisar os dados estatísticos e espaciais apresentados pelo IBGE (2010) e do Ministério das Cidades (Brasil, 2011) e com os argumentos apresentados pelos autores das obras consultadas, que de fato essa "crise" é causada pela má de gestão de nossos recursos hídricos, bem como decorrente do baixo investimento financeiro e tecnológico, seja ele público ou privado, na ampliação e melhoria dos serviços de abastecimento de água.

Diante desse verdadeiro paradoxo da água na região das águas, em que a metade de seus $15.864,454$ habitantes (IBGE, 2010) ainda não tinha acesso a serviços públicos ou 
privados de abastecimento de água, como os moradores das medias e pequenas cidades do interior, das periferias das capitais, sobretudo na zona rural, só nos resta alertar as autoridades governamentais e lideranças políticas nacionais e regionais sobre o risco de um eminente conflito interno e externo pelo controle do acesso e do uso da água na Amazônia brasileira.

A água não deve ser entendida aqui apenas como mais um recurso natural transformado em mercadoria, como outrora defenderam teses do neoliberalismo econômico. Ela deve ser aceita e compreendida como um bem de direito universal de todos, tendo, mais do que valor econômico ou simbólico, um valor espiritual, sanitário, cultural, alimentar e de saúde pública. A água deve ser tratada como um patrimônio da humanidade, sem restrição de acesso aos povos, em particular aos da Amazônia brasileira.

\section{Referências}

ANA. AGÊNCIA NACIONAL DAS ÁGUAS. Atlas Brasil: abastecimento urbano de água - resultados por estados. Brasilia: ANA/Engecorps/Cobrape, 2010. v. 2.

BARLOW, M. Água: futuro azul - como proteger a água potável para o futuro das pessoas e do planeta para sempre. São Paulo: M. Books, 2015.

Água: pacto azul - a crise global da água e a batalha pelo controle da água potável no mundo. São Paulo: M. Books, 2009.

; CLARK, T. Ouro azul: como as grandes corporações estão se apoderando da água doce do nosso planeta. São Paulo: M. Books, 2003.

BECKER, B. Inserção da Amazônia na geopolítica da água. In: ARAGÓN, L.; CLUSENER-GODT, M. (Org.). Problemática do uso local e global da água da Amazônia. Belém: Unesco/Naea/UFPA, 2003. p. 273-298.

BORDALO, C. A "crise" mundial da água vista numa perspectiva da geografia política. Geousp - Espaço e Tempo (Online), São Paulo, n. 31. p. 66-78, 2012.

A gestão dos recursos hídricos à luz da ecologia política: um debate sobre o controle público versus o controle privado da água no Brasil. Cuadernos de Geografía: Revista Colombiana de Geografía, Bogotá, n. 17, p. 117-125, 2008.

et al. O paradoxo da água na Amazônia brasileira. A população sem água na região das águas: o caso da Região Metropolitana de Belém-PA. Revista Equador, Teresina, v. 4, n. 3, p. 595-603, 2015. Edição Especial: XVI Simpósio Brasileiro de Geografia Física Aplicada. Disponível em: http://www.ojs.ufpi.br/index.php/ 
equador. Acesso em: 12.03.2017.

. et al. Os desafios da gestão das águas nas metrópoles da Amazônia: uma análise do modelo de gestão pública dos sistemas de abastecimento de água na Região Metropolitana de Belém, PA. Geonorte, Manaus, v. 3, n. 4, p. 1181-1193, 2012. Edição Especial.

BOUGUERRA, M. As batalhas da água: por um bem comum da humanidade. Petrópolis, RJ: Vozes, 2004.

BRASIL. Ministério das Cidades. Secretaria Nacional de Saneamento Ambiental. Sistema Nacional de Informações sobre Saneamento. Diagnóstico dos serviços de água e esgotos - 2005 e 2009. Brasília: SNSA/MCidades, 2011.

. Ministério das Cidades. Secretaria Nacional de Saneamento Ambiental. Sistema Nacional de Informações sobre Saneamento. Diagnóstico dos serviços de água e esgotos 2011. Brasília: SNSA/MCidades, 2013.

GLEICK, P. The World's Water (1998-1999): The Biennial Report on Freshwater Resources. Washington: Island Press, 1998.

IBGE. INSTITUTO BRASILEIRO DE GEOGRAFIA E ESTATÍSTICA. Atlas de Saneamento. Rio de Janeiro, 2011.

INSTITUTO BRASILEIRO DE GEOGRAFIA E ESTATÍ́STICA. Censo demográfico 2010. Rio de Janeiro: IBGE, 2010a.

. INSTITUTO BRASILEIRO DE GEOGRAFIA E ESTATÍSTICA. Diretoria de Pesquisas, Coordenação de População e Indicadores Sociais. Pesquisa Nacional de Saneamento Básico 2000-2008. Rio de Janeiro, 2010 b.

INSTITUTO TRATA BRASIL. Ranking do saneamento: resultados com base no SNIS 2012. São Paulo, 2014.

Ranking do saneamento: resultados com base no SNIS 2009. São Paulo, 2011.

Ranking do saneamento: resultados com base no SNIS 2005. São Paulo, 2009.

ONU. ORGANIZACIÓN DE LAS NACIONES UNIDAS. Agua para todos, agua para vida. Informe de las Naciones Unidas sobre el Desarrollo de los Recursos Hídricos en el Mundo - ONU/WWDR. Paris: Unesco/ONU/WWAP, 2003. 
- ORGANIZACIÓN DE LAS NACIONES UNIDAS. Programa Mundial de Evaluación de los Recursos Hídricos - ONU/WWAP. Coloquemos las piezas juntos. El Programa Mundial de Evaluación de los Recursos Hídricos. Al servicio del desarrollo, el fortalecimiento de capacidades y el medio ambiente. Paris: Unesco/ONU/WWAP, 2001.

PETRELLA, R. A água: o desafio do bem comum. In: NEUTZLING, I. (Org.). Água: bem público universal. São Leopoldo: Unisinos, 2004. p. 9-32. (Coleção Humanitas).

. O manifesto da água: argumentos para um contrato mundial. Petrópolis, RJ: Vozes, 2002.

PNRH. PLANO NACIONAL DE RECURSOS HÍDRICOS. Águas para o futuro: cenário para 2010. Brasília: MMA/Secretaria de Recursos Hídricos, 2006. v. 2.

. PLANO NACIONAL DE RECURSOS HÍDRICOS. Documento base de referência (minuta). Brasília: MMA/Secretaria de Recursos Hídricos, 2003.

RIBEIRO, W. Geografia política da água. São Paulo: Annablume, 2008.

SHIVA, V. Guerra por água: privatização, poluição e lucro. São Paulo: Radical livros, 2006.

SIQUEIRA, J. Ideologia da água e privatização dos serviços de saneamento: administrando a água como se fosse importante. São Paulo: Senac, 2005. p. 37-45.

UNESCO. UNITED NATIONS EDUCATIONAL, SCIENTIFIC AND CULTURAL ORGANIZATION. The United Nations World Water Development Report 4: Managing Water under Uncertainty and Risk (v. 1), Knowledge Base (v. 2) and Facing the Challenges (v. 3). Washington, 2012.

UN WATER. Día Mundial del Agua, 22 mar. 2010. Agua limpia para un mundo sano. Coordinación del Día Mundial del Agua. Disponível em: http://www.unwater.org/ wwd10/downloads/WWD2010 LOWRES BROCHURE ES.pdf. Acesso em: $7 \mathrm{abr}$. 2017. 